\title{
Identification of significant biomarkers and pathways associated with gastric carcinogenesis by whole genome-wide expression profiling analysis
}

\author{
HONG-JUN FEI, SONG-CHANG CHEN, JUN-YU ZHANG, SHU-YUAN LI, \\ LAN-LAN ZHANG, YI-YAO CHEN, CHUN-XIN CHANG and CHEN-MING XU \\ Department of Reproductive Genetics, International Peace Maternity and Child Health Hospital, \\ Shanghai Jiao Tong University School of Medicine, Shanghai 200030, P.R. China
}

Received October 9, 2017; Accepted January 4, 2018

DOI: 10.3892/ijo.2018.4243

\begin{abstract}
The incidence of gastric cancer (GC) is extremely high in East Asia. GC is also one of the most common and lethal forms of cancer from a global perspective. However, to date, we have not been able to determine one or several genes as biomarkers in the diagnosis of GC and have also been unable to identify the genes which are important in the therapy of GC. In this study, we analyzed all genome-wide expression profiling arrays uploaded onto the Gene Expression Omnibus (GEO) database to filtrate the differentially expressed genes (DEGs) between normal stomach tissues and GC tissues. GSE13911, GSE19826 and GSE79973 were based on the GPL570 platform, and GSE29272 was based on the GPL96 platform. We screened out the DEGs from the two platforms and by selecting the intersection of these two platforms, we identified the common DEGs in the sequencing data from different laboratories. Finally, we obtained 3 upregulated and 34 downregulated DEGs in GC from 384 samples. As the number of downregulated DEGs was greater than that of the upregulated DEGs, functional analysis and pathway enrichment analysis were performed on the downregulated DEGs. Through our analysis, we identified the most significant genes associated with GC, such as secreted phosphoprotein 1 (SPP1), sulfatase 1 (SULF1), thrombospondin 2 (THBS2), ATPase $\mathrm{H}^{+} / \mathrm{K}^{+}$transporting beta subunit $(A T P 4 B)$, gastric intrinsic factor $(G I F)$ and gastrokine $1(G K N I)$. The prognostic power
\end{abstract}

Correspondence to: Professor Chen-Ming Xu, Department of Reproductive Genetics, International Peace Maternity and Child Health Hospital, Shanghai Jiao Tong University School of Medicine, 910 Hengshan Road, Shanghai 200030, P.R. China

E-mail: chenming_xu2006@163.com

Abbreviations: GC, gastric cancer; $\log _{2} \mathrm{FC}, \log _{2}$ fold change/logarithm of fold change; DEGs, differentially expressed genes; BP, biological process; GO, gene ontology; KEGG, Kyoto Encyclopedia of Genes and Genomes; OS, overall survival

Key words: gastric cancer, differentially expressed genes, tumor biomarkers, genome-wide expression profiling, function analysis of these genes was corroborated in the Oncomine database and by Kaplan-Meier plotter (KM-plotter) analysis. Moreover, gastric acid secretion, collecting duct acid secretion, nitrogen metabolism and drug metabolism were significantly related to GC. Thus, these genes and pathways may be potential targets for improving the diagnosis and clinical effects in patients with GC.

\section{Introduction}

Gastric cancer (GC) is the third leading cause of cancerrelated mortality in both sexes worldwide $(723,000$ deaths, $8.8 \%$ of the total). The highest estimated mortality rates are in Eastern Asia, and the lowest in Northern America (1). The GSE series that we finally screened out included 315 samples from China and only 69 samples from Italy, indicating the high incidence of GC in Asian countries. The cause of death in patients with GC is mostly due to late diagnosis, rapid metastatic spread and the limited effectiveness of available therapeutics (2). As regards the diagnosis of GC, histopathological diagnosis remains the gold standard thus far; however, contrast-enhanced ultrasound is useful in the differential diagnosis of gastric subepithelial lesions and can guide further management and follow-up (3-5). Nevertheless, the identification of one or several genes as biomarkers for application in the non-invasive tumor molecular diagnosis of GC, and the better understanding of GC pathogenesis is essential for the establishment of diagnostic markers, as well as novel therapeutic methods. In the treatment of GC, surgery alone is often not very effective (6), even in patients with relatively early stages of the disease. In an attempt to reduce systemic recurrence following surgery alone, adjuvant chemotherapy has been used in trials (7); however, the effects are still limited (8). We thus are eager to establish more effective diagnostic and treatment strategies by examining GC at the genetic level. As the pathogenesis of GC involves the dysfunction of molecular signaling pathways, many efforts have been undertaken in recent years to emphasize the molecular heterogeneity responsible for the process of carcinogenesis $(9,10)$. Currently, some of these aberrant molecular signaling pathways are utilized as targets of interventions with novel therapeutic agents, some of which 
are already used in the treatment of GC, while others remain in the phase of clinical trials (11). In this study, through our results of data analysis, we aimed to shed light on the identification of potential diagnostic and therapeutic markers for GC.

The high-throughput platforms for the analysis of gene expression, such as expression profiling microarrays (12), are increasingly valued as promising tools in medical oncology with great clinical applications (13-15). During the analysis of whole genome sequencing results from different laboratories, the statistical power is increased and the predictive power is more accurate; moreover, the bias of individual studies can be overcome. The aim of this study was to identify potential significant biomarkers for the diagnosis and treatment of GC. For this purpose, we analyzed the genomic signature of human GC.

In the present study, we downloaded the original data (GSE13911, GSE19826, GSE79973 and GSE29272) from Gene Expression Omnibus (GEO), which is a database repository which archives and serves as a hub for microarray data deposit and retrieval (16). Subsequently, the differentially expressed genes (DEGs) were screened using R language. To better clarify the pathological mechanisms, we performed functional analysis and pathway enrichment analysis, such as Gene Ontology (GO) and Kyoto Encyclopedia of Genes and Genomes (KEGG) pathway enrichment analysis for common DEGs screened from the 4 datasets (17). We hope that our findings will provide further insight into gastric carcinogenesis at the molecular level and may aid in the identification of novel potential candidate biomarkers for diagnosis, prognosis and drug targets in GC.

\section{Materials and methods}

Microarray data preprocessing. The microarray gene expression data were derived from searches using 'astric cancer array' and 'human [organism]' and 'expression profiling by array [dataset type]' as the keywords in the GEO database of the National Center for Biotechnology Information (http://www.ncbi.nlm.nih.gov/geo/). There are 135 results under this search condition. Among these, there are 4 types of expression profiling arrays, including genome-wide expression profiling, exon-level expression profiling, cDNA chip and oligonucleotide microarray, which contain 23 GEO series comparing differences between normal stomach tissues and GC tissues. The classification and summary of the GEO series are presented in Table I.

We conducted genome-wide analysis of gene expression between normal stomach tissues and GC tissues shown as the first row in Table I. Four independent datasets from 2 platforms were used for analysis, which are introduced in Table II. Three of these (GSE13911, GSE19826 and GSE79973) were based on the GPL570 platform, which tested the expression values of 21,755 genes. Thus, we merged the gene expression data of 116 patients from the 3 datasets based on the gene symbol to perform further analysis. A 4th dataset, GSE29272, based on the GPL96 platform was analyzed separately; it tested the expression values of 13,102 genes. The process of data filing is shown in Fig. 1.

Data preprocessing prior to difference analysis. We utilized the robust multi-array average algorithm of the affy package
Table I. A classification and summary was made of the expression profiling array between the normal stomach and gastric cancer in the GEO database.

\begin{tabular}{lcl}
\hline & Platforms & GEO accession no. \\
\hline $\begin{array}{l}\text { Genome-wide expression } \\
\text { profiling }\end{array}$ & 2 & $\begin{array}{l}\text { GSE13911, GSE19826 } \\
\text { cDNA microarrays }\end{array}$ \\
$\begin{array}{lcl}\text { GSE79973, GSE29272 } \\
\text { profiling }\end{array}$ & 5 & $\begin{array}{l}\text { GSE2637, GSE2669 } \\
\text { GSE17154, GSE33429 }\end{array}$ \\
& 2 & GSE13195, GSE27342 \\
Oligonucleotide & & GSE33335, GSE33429 \\
microarray & & GSE56807, GSE63089 \\
& 7 & GSE20143, GSE2685 \\
& & GSE49051, GSE38932 \\
& & GSE33651, GSE37023 \\
& GSE38940
\end{tabular}

GEO, Gene Expression Omnibus.

in $\mathrm{R}$ language to convert the raw data of 4 CEL files into expression data. The expression levels of the probe sets were converted into gene expression levels by the Bioconductor annotation function of $\mathrm{R}$ language according to different platforms. The expression values of multiple probes for a given gene were averaged. With this, we obtained 4 tables containing the expression values of different genes in different patients based on the 4 GEO series. The function termed SameGene in $\mathrm{R}$ language was then used to merge the gene expression data of 116 patients from the GSE13911, GSE19826 and GSE79973 datasets according to the gene symbol as 1 table. In addition, we now had 2 tables, one from the GSE13911, GSE19826 and GSE79973 datasets, and another from the GSE29272 dataset. Batch normalization was conducted on all expression profiling data using ComBat algorithm in Surrogate Variable Analysis package of $\mathrm{R}$ language. The normalization can eliminate the systematic variations among studies.

Screening of DEGs. The candidate genes of GC tumors and normal stomach tissues were analyzed using the linear models for microarray data (Limma) package in Bioconductor (http:// www.bioconductor.org/packages/release/bioc/html/limma.html). Results with a $\log _{2}$ fold changel $\left(\log _{2} \mathrm{FCl}\right)>2$ and an adjusted P-value $<0.05$ were considered significant.

GO and KEGG pathway enrichment analysis for DEGs. The Database for Annotation, Visualization and Integrated Discovery (DAVID, http://david.abcc.ncifcrf.gov/) is characterized by functional annotation and biological interpretation for genome-scale datasets, which improve an integrated and high throughput data mining environment. To evaluate the involvement of DEGs in functional and metabolic pathways, DAVID was utilized to perform GO and KEGG enrichment analysis for downregulated DEGs (following the intersection of the DEGs screened from 2 sequencing platforms) with a P-value $<0.05$ as a strict cut-off. The aim of GO (http://www.geneontology.org/) 
Table II. Genome-wide expression profiling arrays which analyzed the differences between normal stomach and gastric cancer (GC) tissues were introduced.

\begin{tabular}{|c|c|c|c|}
\hline $\begin{array}{l}\text { Expression profiling array } \\
\text { (Normal stomach and gastric cancer) }\end{array}$ & Platforms & GEO accession no. & Samples \\
\hline \multirow[t]{4}{*}{ Genome } & GPL570 & GSE13911 & 31 normal; $38 \mathrm{GC}$ \\
\hline & & GSE19826 & 15 normal; $12 \mathrm{GC}$ \\
\hline & & GSE79973 & 10 normal; $10 \mathrm{GC}$ \\
\hline & GPL96 & GSE29272 & 134 normal; 134 GC \\
\hline
\end{tabular}

GEO, Gene Expression Omnibus.

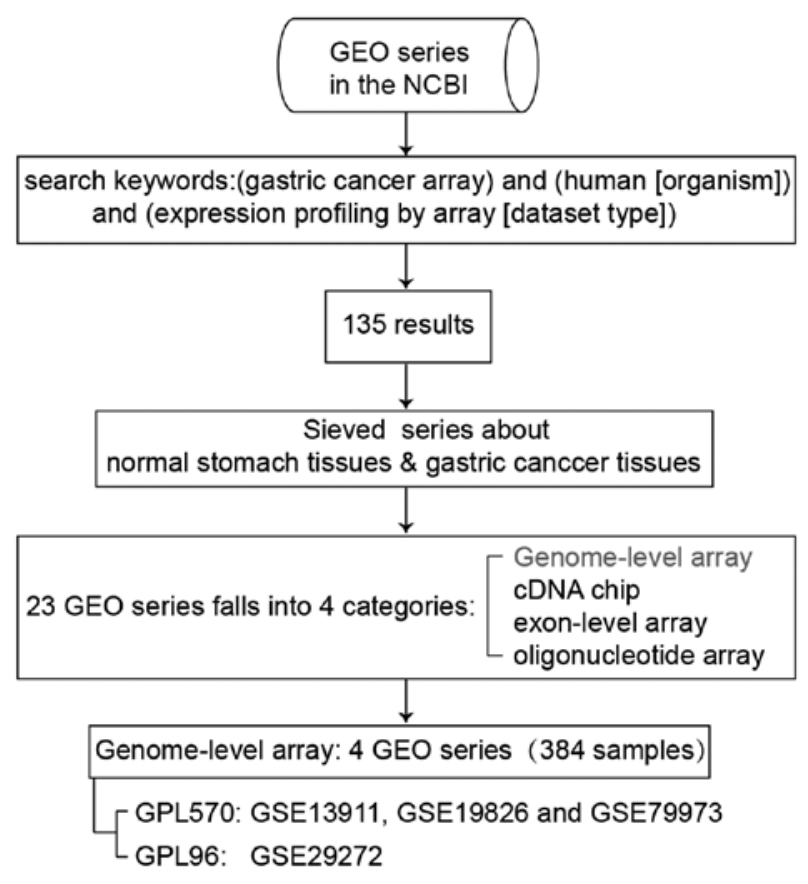

Figure 1. Process of pooling 4 microarray gene expression datasets.

is to provide access to the biological annotation of genes, gene products and sequences. GO terms consist of 3 categories: Biological process (BP), cellular component (CC) and molecular function (MF). Our analyses were focused predominantly on BP. A value of $\mathrm{P}<0.05$ was used as the cut-off criterion. KEGG (http://www.genome.ad.jp/kegg/) is a comprehensive database resource, which consists of chemical information, genomic information and systems information.

Venn diagram. We used the Venn diagram (http://bioinfogp. cnb.csic.es/tools/venny/) to screen out the common DEGs in different experiments.

Oncomine database analysis and Kaplan-Meier plotter analysis for DEGs. The expression levels of the common DEGs obtained from the 2 sequencing platforms in GC were analyzed using the Oncomine Cancer Profiling Database (https://www. oncomine.org) $(18,19)$. The mRNA expression fold in cancer tissue compared to normal tissue was obtained and compared. For survival analyses, the prognostic value of the selected DEGs in GC were analyzed using Kaplan-Meier Plotter (http://kmplot.com/analysis/) and tested for significance using log-rank tests $(20,21)$. The analysis was performed according to the manufacturer's instructions [http://kmplot.com/analysis/index.php?p (21)].

\section{Results}

Normalization of gene expression values. A total of 21,755 genes from 116 samples were normalized with median method following batch normalization. The results before and after normalization are shown by the top and bottom box figures describing the expression values of the 116 samples in Fig. 2A. The horizontal axis stands for sample names.

A total of 13,102 genes from 268 samples were normalized in a similar manner. The results before and after normalization are shown by the top and bottom box figures describing the expression values of 268 samples in Fig. 2B. The horizontal axis stands for sample names shown in Fig. 2B for 3 rows.

The vertical axis stands for gene expression values. The black horizontal line represents the median of expression value of the sample, which is almost on a straight line after batch normalization, suggesting that normalized data were qualified.

Selection of DEGs. We used R Limma package software to analyze which gene sets were deregulated in both comparisons with the threshold of $\log _{2} \mathrm{FCl}>2$ and $\mathrm{P}<0.05$. The DEGs were identified using the t-test statistical algorithm. The significant genes lists were selected according to their fold changes in expression values.

In the first group of data that contained 3 GEO series from GPL570 (116 samples), a total of 224 DEGs between 60 GC samples and 56 normal controls were screened, which included 59 upregulated genes and 165 downregulated genes. The number of downregulated genes was higher than that of upregulated genes. In Table III, we list the first 40 genes with the most obvious fold changes in expression values. A heatmap of hierarchical clustering of the top 50 screened DEGs was drawn according to the P-value (Fig. 3A). Fig. 3B shows a volcano plot of gene expression differences between the GC tissues and controls. The y-axis in the volcano plot represents the distributions of fold change $\left[\left(\log _{2}\right.\right.$ (fold change)] and the $\mathrm{X}$-axis resprents the $\mathrm{P}$-values $\left[-\log _{10}\right.$ (P-value)].

In another group of data that contained $1 \mathrm{GEO}$ series from GPL96 (268 samples), a total of 37 DEGs between 134 GC samples and 134 normal controls were screened, which included 7 upregulated genes and 35 downregulated genes. 

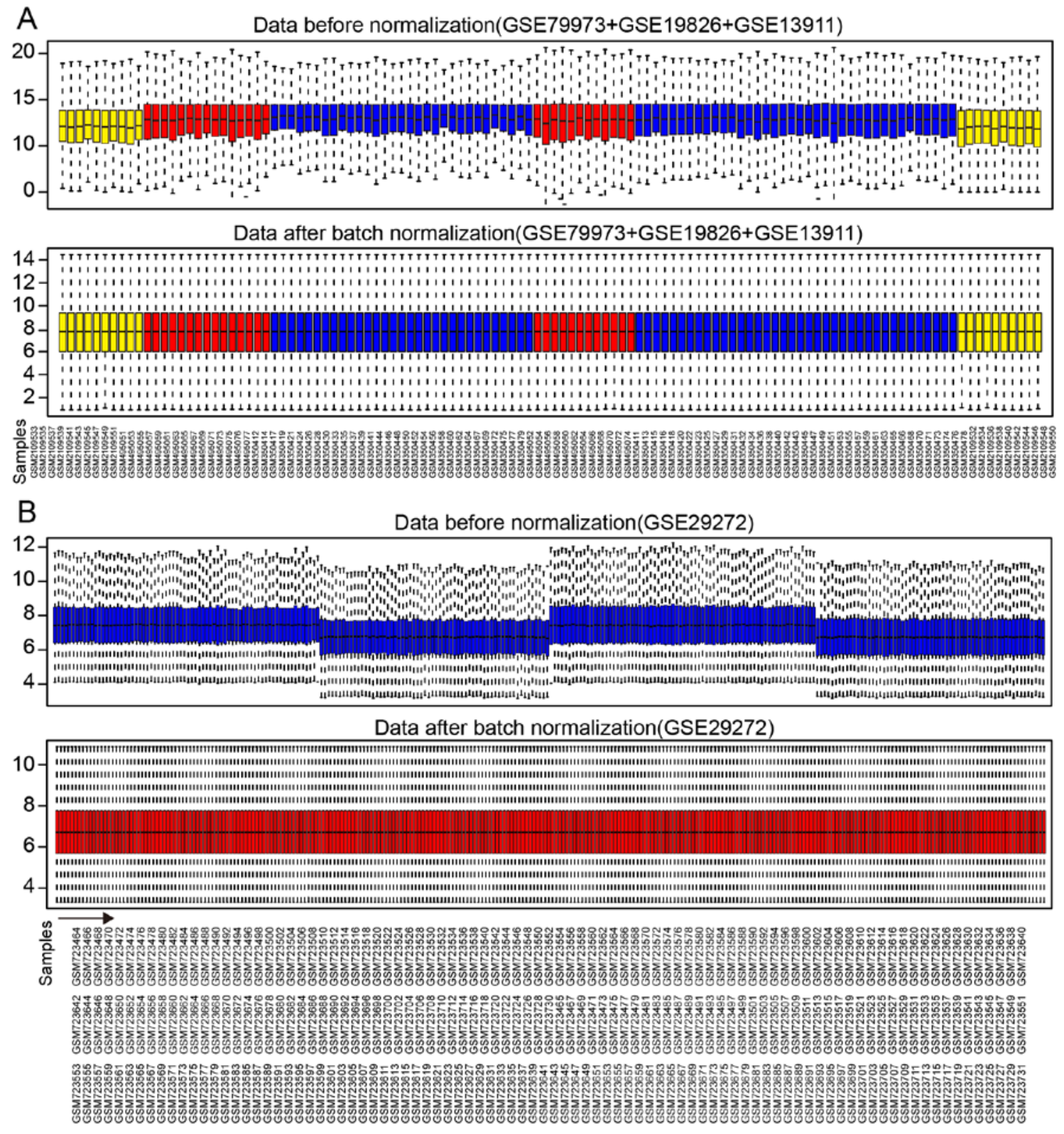

Figure 2. Box figures of the expression values of all genes before and after normalization. (A) The results before and after normalization are shown by the top and bottom box-plots describing the expression values of 116 samples from GSE13911, GSE19826 and GSE79973 datasets. The yellow column represents the sample from GSE79973. The red column represents the sample from GSE19826. The blue column represents the sample from GSE13911. The 3 groups (yellow, red and blue) on the left were normal stomach tissues and the 3 groups (red, blue and yellow) on the right were gastric cancer tissues. (B) The results before and after normalization are shown by the top and bottom box-plots describing the expression values of 268 samples from the GSE29272 dataset.

All these are listed in Table IV. A heatmap of hierarchical clustering of all the screened DEGs was drawn according to the P-value (Fig. 4A). Fig. 4B depicts the volcano plot of gene expression differences between the GC tissues and controls. The $y$-axis in the volcano plot represents the distributions of fold change $\left[\left(\log _{2}\right.\right.$ (fold change) $)$ and the $\mathrm{x}$-axis represents the P-values $\left[-\log _{10}\right.$ (P-value)] (Fig. 4B).

The top 40 DEGs, either up- or downregulated DEGS, screened between the normal stomach tissues and GC tissues from the different sequencing platforms are shown in Tables III and IV, respectively.

We then wished to identify the common DEGs that were screened out from the different sequencing platforms. Using the Venn diagram (http://bioinfogp.cnb.csic.es/tools/venny/), we found the intersection of the DEGs screened from two sequencing platforms; there were 3 upregulated DEGs (Fig. 4C and Table V) and 34 downregulated DEGs (Fig. 4C and Table VI) in GC. The number of downregulated DEGs was higher than that of upregulated DEGs.

GO analysis and KEGG pathway analysis of screened $D E G s$. Following the intersection of the DEGs which were screened out from the two sequencing platforms, the number of downregulated DEGs were greater than that of upregulated DEGs. Thus, function analyses were performed on the downregulated DEGs. For the downregulated DEGs, the enriched functions in the BP category were enriched in the digestion process, cellular aldehyde metabolic process, oxidation-reduction process, potassium ion import and so on (Table VII). 
Table III. Top 40 DEGs, either up- and downregulated in gastric cancer (GC), screened between non-cancerous tissues and GC tissues from GSE13911, GSE19826 and GSE79973.

\begin{tabular}{|c|c|c|}
\hline Gene & $\log _{2} \mathrm{FC}$ & P-value \\
\hline \multicolumn{3}{|c|}{ Upregulated genes } \\
\hline CST1 & 4.136321 & $5.63 \mathrm{E}-17$ \\
\hline FNDC1 & 3.952541 & $1.32 \mathrm{E}-16$ \\
\hline CDH3 & 3.731233 & $5.88 \mathrm{E}-20$ \\
\hline COL11A1 & 3.704572 & $2.03 \mathrm{E}-14$ \\
\hline INHBA & 3.670232 & $1.10 \mathrm{E}-23$ \\
\hline FAP & 3.564285 & $1.32 \mathrm{E}-21$ \\
\hline COL10A1 & 3.343815 & $1.11 \mathrm{E}-16$ \\
\hline SERPINH1 & 3.270653 & $9.50 \mathrm{E}-24$ \\
\hline HOXA10 & 3.219003 & $4.59 \mathrm{E}-16$ \\
\hline ZIC2 & 3.189131 & $6.84 \mathrm{E}-11$ \\
\hline SPP1 & 3.0706 & $8.69 \mathrm{E}-16$ \\
\hline CLDN7 & 2.995307 & $4.00 \mathrm{E}-11$ \\
\hline THBS2 & 2.856412 & $2.44 \mathrm{E}-16$ \\
\hline CLDN1 & 2.756577 & $1.75 \mathrm{E}-18$ \\
\hline CEMIP & 2.756077 & $1.36 \mathrm{E}-16$ \\
\hline COL8A1 & 2.724625 & $5.75 \mathrm{E}-20$ \\
\hline MAGEA6 & 2.716267 & $1.71 \mathrm{E}-06$ \\
\hline FKBP10 & 2.667536 & $1.33 \mathrm{E}-14$ \\
\hline CXCL8 & 2.602867 & $1.36 \mathrm{E}-10$ \\
\hline LY6E & 2.556012 & $1.51 \mathrm{E}-10$ \\
\hline SULF1 & 2.555768 & $1.41 \mathrm{E}-19$ \\
\hline CLDN3 & 2.555489 & $3.26 \mathrm{E}-07$ \\
\hline HOXC6 & 2.484315 & $2.63 \mathrm{E}-13$ \\
\hline MFAP2 & 2.460753 & $2.18 \mathrm{E}-18$ \\
\hline EPHX4 & 2.404839 & $2.86 \mathrm{E}-11$ \\
\hline KRT80 & 2.378706 & $8.59 \mathrm{E}-12$ \\
\hline S100A2 & 2.367957 & 1.03E-09 \\
\hline PLA2G2A & 2.353902 & $8.66 \mathrm{E}-06$ \\
\hline SFRP4 & 2.316553 & 8.92E-13 \\
\hline FOXM1 & 2.309926 & $3.46 \mathrm{E}-10$ \\
\hline CTHRC1 & 2.309915 & $1.36 \mathrm{E}-14$ \\
\hline EFNA3 & 2.306238 & $7.89 \mathrm{E}-12$ \\
\hline CLRN3 & 2.296356 & $4.36 \mathrm{E}-05$ \\
\hline RARRES1 & 2.281905 & $2.83 \mathrm{E}-12$ \\
\hline DUXAP10 & 2.249024 & $2.43 \mathrm{E}-12$ \\
\hline HCAR3 & 2.24534 & 7.20E-06 \\
\hline HOXA13 & 2.240626 & $3.54 \mathrm{E}-12$ \\
\hline CLDN2 & 2.215066 & 2.20E-09 \\
\hline CDH17 & 2.214023 & 0.0004725 \\
\hline CDCA5 & 2.190493 & $4.38 \mathrm{E}-12$ \\
\hline \multicolumn{3}{|c|}{ Downregulated genes } \\
\hline ATP4A & -6.71606 & $2.73 \mathrm{E}-20$ \\
\hline GIF & -6.67442 & $1.12 \mathrm{E}-19$ \\
\hline ATP4B & -6.08217 & $1.24 \mathrm{E}-19$ \\
\hline GKN1 & -5.83921 & $6.77 \mathrm{E}-13$ \\
\hline PGA4 & -5.53179 & $2.10 \mathrm{E}-15$ \\
\hline LIPF & -5.47762 & $8.17 \mathrm{E}-15$ \\
\hline GKN2 & -5.40202 & $2.64 \mathrm{E}-14$ \\
\hline KCNE2 & -5.16124 & $3.00 \mathrm{E}-17$ \\
\hline
\end{tabular}

Table III. Continued.

\begin{tabular}{|c|c|c|}
\hline Gene & $\log _{2} \mathrm{FC}$ & P-value \\
\hline SOSTDC1 & -4.92959 & $1.71 \mathrm{E}-16$ \\
\hline CHIA & -4.82975 & $1.01 \mathrm{E}-13$ \\
\hline ESRRG & -4.60677 & $2.72 \mathrm{E}-19$ \\
\hline LTF & -4.46097 & $3.29 \mathrm{E}-11$ \\
\hline KCNJ16 & -4.1163 & $3.48 \mathrm{E}-20$ \\
\hline CHGA & -4.09923 & $1.51 \mathrm{E}-16$ \\
\hline CWH43 & -4.08608 & $1.32 \mathrm{E}-21$ \\
\hline AQP4 & -4.06294 & $2.90 \mathrm{E}-17$ \\
\hline PGC & -4.03877 & $1.64 \mathrm{E}-11$ \\
\hline PSCA & -4.03647 & $1.06 \mathrm{E}-12$ \\
\hline C16orf89 & -4.01438 & $1.50 \mathrm{E}-15$ \\
\hline SCGB2A1 & -3.98484 & $5.57 \mathrm{E}-13$ \\
\hline FUT9 & -3.95876 & $9.17 \mathrm{E}-16$ \\
\hline SH3GL2 & -3.9198 & $1.71 \mathrm{E}-16$ \\
\hline LINC00261 & -3.9137 & $6.26 \mathrm{E}-13$ \\
\hline DPCR1 & -3.88239 & $9.90 \mathrm{E}-15$ \\
\hline SST & -3.84699 & $2.84 \mathrm{E}-13$ \\
\hline ETNPPL & -3.82884 & $1.47 \mathrm{E}-13$ \\
\hline CXCL17 & -3.80482 & $8.66 \mathrm{E}-12$ \\
\hline TMED6 & -3.78841 & $1.16 \mathrm{E}-11$ \\
\hline MFSD4A & -3.76152 & $4.91 \mathrm{E}-17$ \\
\hline FBP2 & -3.70113 & $4.23 \mathrm{E}-14$ \\
\hline PDILT & -3.69747 & $2.57 \mathrm{E}-12$ \\
\hline VSIG1 & -3.64013 & $3.35 \mathrm{E}-14$ \\
\hline MAP7D2 & -3.49454 & $1.36 \mathrm{E}-14$ \\
\hline CPA2 & -3.44653 & $1.20 \mathrm{E}-16$ \\
\hline MSMB & -3.42457 & $1.25 \mathrm{E}-06$ \\
\hline FAM3B & -3.33335 & $9.35 \mathrm{E}-10$ \\
\hline ANXA10 & -3.31144 & $5.34 \mathrm{E}-11$ \\
\hline KRT20 & -3.30519 & $4.26 \mathrm{E}-10$ \\
\hline $\mathrm{GC}$ & -3.30434 & $2.69 \mathrm{E}-11$ \\
\hline SLC26A9 & -3.30012 & $2.61 \mathrm{E}-16$ \\
\hline
\end{tabular}

There are 59 upregulated genes ( $\log _{2}$ fold change $>2$ ) and 40 with the greatest changes in expression are listed. There are also 165 downregulated genes ( $\log _{2}$ fold changel $>2$ ) and 40 with the greatest changes in expression are listed. DEGs, differentially expressed genes.

To better clarify the pathological mechanisms, we performed KEGG enrichment analysis. According to the results of KEGG pathway enrichment analysis, the downregulated genes were significantly enriched in gastric acid secretion $(\mathrm{P}=8.8 \mathrm{E}-7)$, collecting duct acid secretion $(\mathrm{P}=2.2 \mathrm{E}-3)$ and nitrogen metabolism $(\mathrm{P}=4.3 \mathrm{E}-2)$ (Table VIII).

Overall survival (OS) analysis of common DEGs. To clarify whether the expression value of the common DEGs correlated with cancer progression, we first analyzed the expression levels of the common DEGs with the cancer microarray database, Oncomine. There were 37 common DEGs screened from two sequencing platforms, 3 upregulated DEGs and 34 downregulated DEGs. We selected 3 downregulated DEGs which had most 


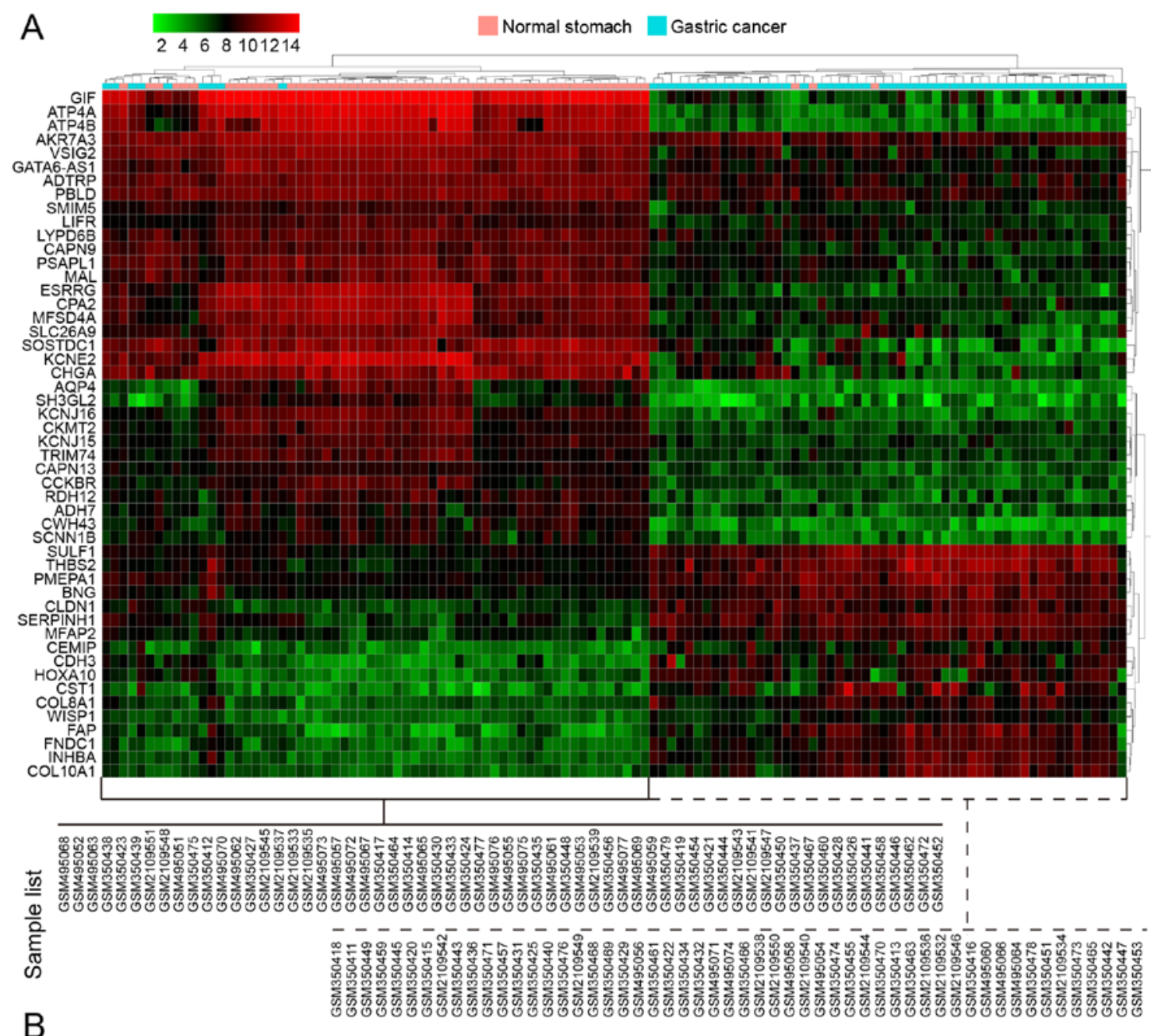

B

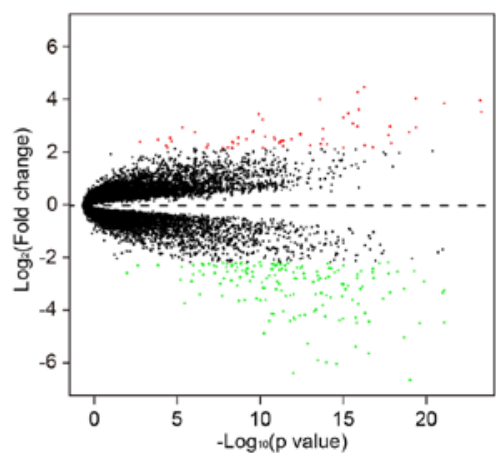

Figure 3. Results of differentially expressed genes (DEGs) filtered from 3 GEO series (GSE13911, GSE19826 and GSE79973) on platform of GPL570. (A) Heatmap of the top 50 DEGs. (B) Volcano plot of gene expression differences between gastric cancer (GC) tissues and controls. The red spots represent upregulated genes with a $\log _{2}$ (fold change)l of $>2$, and the green spots represent the downregulated genes with a $\log _{2}$ (fold change)l of $>2$.

evident fold changes in expression values and 3 common upregulated DEGs to be analyzed. The results revealed that common upregulated DEGs were significantly upregulated in GC tissues $(\mathrm{P}<0.05)$ (Fig. 5A); however, the downregulation of the 3 selected common downregulated DEGs in the GC tissues was not so evident ( $\mathrm{P}>0.05$ ) (Fig. 5B). We then analyzed the expression of common DEGs using Kaplan-Meier plotter analysis. The results revealed that the high expression levels of 3 common upregulated DEGs were associated with a worse prognosis $(\mathrm{P}<0.01)$ (Fig. 5C); however, the association between the downregulated DEGs and OS was not so evident $(\mathrm{P}>0.05)$ (Fig. 5D). The results of common DEGs expressed in the normal stomach and different types of GCs are consistent with predicted results based on GEO database in this study (Fig. 6).

The results reminded us that perhaps in GC, the accumulated expression of certain oncogenes may play an important role in the induction of gastric carcinogenesis, such as the secreted phosphoprotein 1 (SPPl), sulfatase $1(S U L F 1)$ and thrombospondin 2 (THBS2) genes.

\section{Discussion}

GC is a product of cumulative genetic, epigenetic, somatic and endocrine aberrations (22). Understanding the molecular 
Table IV. All DEGs, either up- or downregulated in GC, screened between non-cancerous tissues and gastric cancer tissues from GSE29272.

\begin{tabular}{|c|c|c|}
\hline Gene & $\log \mathrm{FC}$ & $\mathrm{P}$-value \\
\hline \multicolumn{3}{|c|}{ Upregulated genes } \\
\hline SULF1 & 2.270592 & $1.28 \mathrm{E}-73$ \\
\hline TIMP1 & 2.007688 & $5.00 \mathrm{E}-66$ \\
\hline COL1A2 & 2.221719 & $1.03 \mathrm{E}-63$ \\
\hline THBS2 & 2.088207 & $1.70 \mathrm{E}-56$ \\
\hline SPP1 & 2.626177 & $2.00 \mathrm{E}-44$ \\
\hline ASPN & 2.266153 & $4.61 \mathrm{E}-40$ \\
\hline CEACAM6 & 2.044841 & $1.95 \mathrm{E}-19$ \\
\hline \multicolumn{3}{|c|}{ Downregulated genes } \\
\hline ATP4B & -5.99851 & $7.26 \mathrm{E}-82$ \\
\hline GKN1 & -5.59055 & $3.39 \mathrm{E}-68$ \\
\hline GIF & -5.54724 & $1.00 \mathrm{E}-78$ \\
\hline ATP4A & -5.17913 & $1.71 \mathrm{E}-78$ \\
\hline LIPF & -4.90329 & $7.02 \mathrm{E}-53$ \\
\hline PGA4 & -4.39449 & $1.46 \mathrm{E}-57$ \\
\hline CHIA & -3.95282 & $2.18 \mathrm{E}-49$ \\
\hline PGC & -3.76167 & $1.13 \mathrm{E}-45$ \\
\hline AKR1B10 & -3.48351 & $2.40 \mathrm{E}-41$ \\
\hline PSCA & -3.46225 & $7.66 \mathrm{E}-53$ \\
\hline KCNE2 & -3.45857 & $1.46 \mathrm{E}-71$ \\
\hline ANXA10 & -3.45231 & $1.85 \mathrm{E}-45$ \\
\hline TFF2 & -3.31672 & $2.60 \mathrm{E}-42$ \\
\hline ESRRG & -3.31647 & $1.27 \mathrm{E}-70$ \\
\hline MT1M & -3.2643 & $2.29 \mathrm{E}-61$ \\
\hline TFF1 & -3.11946 & $6.46 \mathrm{E}-31$ \\
\hline REG1A & -2.96114 & $1.34 \mathrm{E}-28$ \\
\hline CA2 & -2.928 & $1.37 \mathrm{E}-35$ \\
\hline KCNJ16 & -2.85901 & $1.02 \mathrm{E}-55$ \\
\hline SST & -2.83779 & $1.11 \mathrm{E}-55$ \\
\hline CPA2 & -2.81823 & $5.12 \mathrm{E}-68$ \\
\hline LTF & -2.76326 & $1.75 \mathrm{E}-35$ \\
\hline AZGP1 & -2.65999 & $1.64 \mathrm{E}-39$ \\
\hline SULT1C2 & -2.50941 & $8.22 \mathrm{E}-38$ \\
\hline REG3A & -2.46262 & $1.61 \mathrm{E}-19$ \\
\hline CA9 & -2.37875 & $1.74 \mathrm{E}-60$ \\
\hline MUC5AC & -2.29526 & $1.62 \mathrm{E}-47$ \\
\hline MT1F & -2.27496 & $1.16 \mathrm{E}-57$ \\
\hline CLDN18 & -2.24552 & $1.79 \mathrm{E}-29$ \\
\hline ALDH3A1 & -2.17363 & $5.04 \mathrm{E}-49$ \\
\hline ALDH1A1 & -2.13538 & 4.11E-36 \\
\hline MUC6 & -2.10319 & $3.06 \mathrm{E}-47$ \\
\hline CTSE & -2.04893 & $3.85 \mathrm{E}-25$ \\
\hline TCN1 & -2.03767 & $3.09 \mathrm{E}-24$ \\
\hline AKR7A3 & -2.01921 & $1.95 \mathrm{E}-57$ \\
\hline
\end{tabular}

There are 7 upregulated genes ( $\log _{2}$ fold change $>2$ ) and all are listed. There are also 35 downregulated genes ( $\left(\log _{2}\right.$ fold changel $>2$ ) and all are listed. DEGs, differentially expressed genes.
Table V. Gene list and function of common upregulated genes.

\begin{tabular}{ll}
\hline Gene symbol & \multicolumn{1}{c}{ Gene function } \\
\hline SPP1 & $\begin{array}{l}\text { Cytokine activity/extracellular matrix } \\
\text { binding/protein binding }\end{array}$ \\
THBS2 & $\begin{array}{l}\text { Calcium ion binding/heparin binding/ } \\
\text { protein binding }\end{array}$ \\
& $\begin{array}{l}\text { N-acetylglucosamine-6-sulfatase activity/ } \\
\text { N-acetylglucosamine-6-sulfatase activity/ } \\
\text { arylsulfatase }\end{array}$
\end{tabular}

SPP1, secreted phosphoprotein 1; THBS2, thrombospondin 2; SULF1, sulfatase 1 .

mechanisms of GC is of critical importance for diagnosis and treatment. Since high throughput sequencing $(23,24)$ can reveal the expression levels of thousands of genes in the human genome simultaneously, it has been widely used to predict the potential therapeutic targets for GC (25). By taking into consideration the analysis of whole genome sequencing results from different laboratories, the statistical power can be increased and the prediction may be more accurate; moreover, the bias of individual studies can be overcome. In this study, the common DEGs that were screened out from different sequencing platforms containing 384 samples were listed. There were 3 common upregulated DEGs and 34 common downregulated DEGs in GC with the threshold of $\log _{2} \mathrm{FCl}>2$ and $\mathrm{P}<0.05$. Among these, the expression values of ATPase $\mathrm{H}^{+} / \mathrm{K}^{+}$transporting beta subunit (ATP4B), gastrokine $1(G K N 1)$, gastric intrinsic factor $(G I F)$, ATPase $\mathrm{H}^{+} / \mathrm{K}^{+}$transporting alpha subunit $(A T P 4 A)$, lipase $\mathrm{F}$, gastric type $(L I P F)$ and pepsinogen 4 , group I (pepsinogen A; PGA4) between the GC and normal tissues were altered by $>2^{4}$ fold, and independent of the platform, the fold change expression value of 6 genes was ranked in the top 6. Raja et al found that the downregulation of $A T P 4 A$ and $A T P 4 B$ involved DNA methylation and methylated $A T P 4 B$ DNA in plasma was a potential biomarker for GC (26); to the best of our knowledge, this was the only study to date which investigated the association of $A T P 4 B$ or $A T P 4 A$ with GC and these findings were consistent with our analysis. GKN1 has convergent functions in terms of the modulation of gastric mucosal homeostasis and inflammation, activity in epithelial wound healing or repair, and anti-proliferative activity, and there has been relatively more research on this gene in gastric carcinogenesis (27-30). $G I F$ is a gastric intrinsic factor and $L I P F$ encodes gastric lipase; it is an enzyme involved in the digestion of dietary triglycerides in the gastrointestinal tract, and is responsible for $30 \%$ of fat digestion processes occurring in humans. PGA4 encodes a protein precursor of the digestive enzyme pepsin, a member of the peptidase A1 family of end peptidases. The functional deficiency of these genes can lead to GC $(31,32)$. On the whole, it can be deduced that the DEGs we screened from GC tissues and normal stomach may aid in the investigation of GC and the discovery of novel drugs.

The GO term analysis revealed that the downregulated DEGs were mainly involved in the digestion process, cellular 
Table VI .Gene list and function of common downregulated genes.

Gene

Function

\begin{tabular}{|c|c|}
\hline AKR1B10 & Aldo-keto reductase (NADP) activity/geranylgeranyl reductase activity/indanol dehydrogenase \\
\hline AKR7A3 & Aldo-keto reductase (NADP) activity/electron carrier activity/protein binding \\
\hline ALDH1A1 & GTPase activator activity/aldehyde dehydrogenase (NAD) activity/aldehyde dehydrogenase (NAD) \\
\hline ALDH3A1 & $\begin{array}{l}\text { 3-Chloroallyl aldehyde dehydrogenase activity/alcohol dehydrogenase (NADP }{ }^{+} \text {) activity/aldehyde } \\
\text { dehydrogenase }\end{array}$ \\
\hline ANXA10 & Calcium ion binding/calcium-dependent phospholipid binding/protein binding \\
\hline ATP4A & $\begin{array}{l}\text { ATPbinding/hydrogen:potassium-exchanging ATPase activity/magnesiumion binding/sodium:potassium- } \\
\text { exchanging ATPase activity }\end{array}$ \\
\hline ATP4B & Hydrogen:potassium-exchanging ATPase activity/protein binding \\
\hline AZGP1 & Antigen binding/glycoprotein binding/peptide antigen binding/protein binding/protein transmembrane \\
\hline CA2 & $\begin{array}{l}\text { Arylesterase activity/carbonate dehydratase activity/carbonate dehydratase activity/protein } \\
\text { binding///zinc ion binding }\end{array}$ \\
\hline CA9 & Carbonate dehydratase activity/zinc ion binding \\
\hline CHIA & Carbohydrate binding/chitin binding/chitinase activity/chitinase activity/chitinase activity/kinase \\
\hline CLDN18 & Identical protein binding/structural molecule activity \\
\hline CPA2 & Carboxypeptidase activity/metallocarboxypeptidase activity/zinc ion binding \\
\hline CTSE & Aspartic-type endopeptidase activity/protein homodimerization activity \\
\hline ESRRG & AF-2 domain binding/RNA polymerase II regulatory region sequence-specific DNA binding/protein \\
\hline GIF & Cobalamin binding \\
\hline GKN1 & Molecular function \\
\hline KCNE2 & $\begin{array}{l}\text { Contributes to delayed rectifier potassium channel activity/contributes_to inward rectifier } \\
\text { potassium channel }\end{array}$ \\
\hline KCNJ16 & G-protein activated inward rectifier potassium channel activity/inward rectifier potassium channel \\
\hline LIPF & Lipid binding/malate dehydrogenase activity/triglyceride lipase activity \\
\hline LTF & DNA binding/heparin binding/iron ion binding/protein binding/protein serine/threonine kinase activator \\
\hline MT1M & Zinc ion binding \\
\hline MUC5AC & Extracellular matrix structural constituent \\
\hline MUC6 & Extracellular matrix structural constituent \\
\hline PGA4 & Aspartic-type endopeptidase activity/peptidase activity/aspartic-type endopeptidase activity/peptidase \\
\hline PGC & Aspartic-type endopeptidase activity \\
\hline PSCA & Isoform 2 of Ly6/PLAUR domain-containing protein 1 \\
\hline REG1A & Carbohydrate binding/growth factor activity \\
\hline REG3A & Carbohydrate binding/protein binding \\
\hline SST & Hormone activity \\
\hline SULT1C2 & Aryl sulfotransferase activity/protein binding/sulfotransferase activity/sulfotransferase activity \\
\hline TCN1 & Cobalamin binding \\
\hline TFF1 & Growth factor activity/protein binding \\
\hline TFF2 & Protein binding \\
\hline
\end{tabular}

aldehyde metabolic process (33), oxidation-reduction process, potassium ion import and so on (34). Furthermore, the enriched KEGG pathways of the downregulated DEGs included gastric acid secretion, collecting duct acid secretion and Nnitrogen metabolism. Di Mario and Goni reported that gastric acid secretion was strongly associated with GC (35). Decreased or increased gastric acid secretion can lead to various diseases in the stomach, such as gastroesophageal reflux disease, chronic atrophic gastritis and others (36). Some drugs based on acid secretion, namely the $\mathrm{H}_{2}$-receptor antagonists $\left(\mathrm{H}_{2} \mathrm{RAs}\right)$ and proton pump inhibitors (PPIs), allow for the effective and safe treatment of peptic ulcers and other acid-related disorders (37).
The collecting duct is responsible for the final secretion or re-absorption of protons and bicarbonate, it mediates $\mathrm{Na}, \mathrm{K}$ and water transport and intercalated cells (ICs), which are specialized for acid-base transport (38). To date, to the best of our knowledge, there is no study available on collecting duct acid secretion and GC; however, acid-base balance is often clinically linked (39). The association between collecting duct acid secretion and GC warrants further investigation. Studies have suggested that the implementation of effective nutritional support is crucial for improving the post-operative nutrient consumption and improving prognosis, as well as the quality of rehabilitation in patients with GC (40). Ishizuka et al (41) 

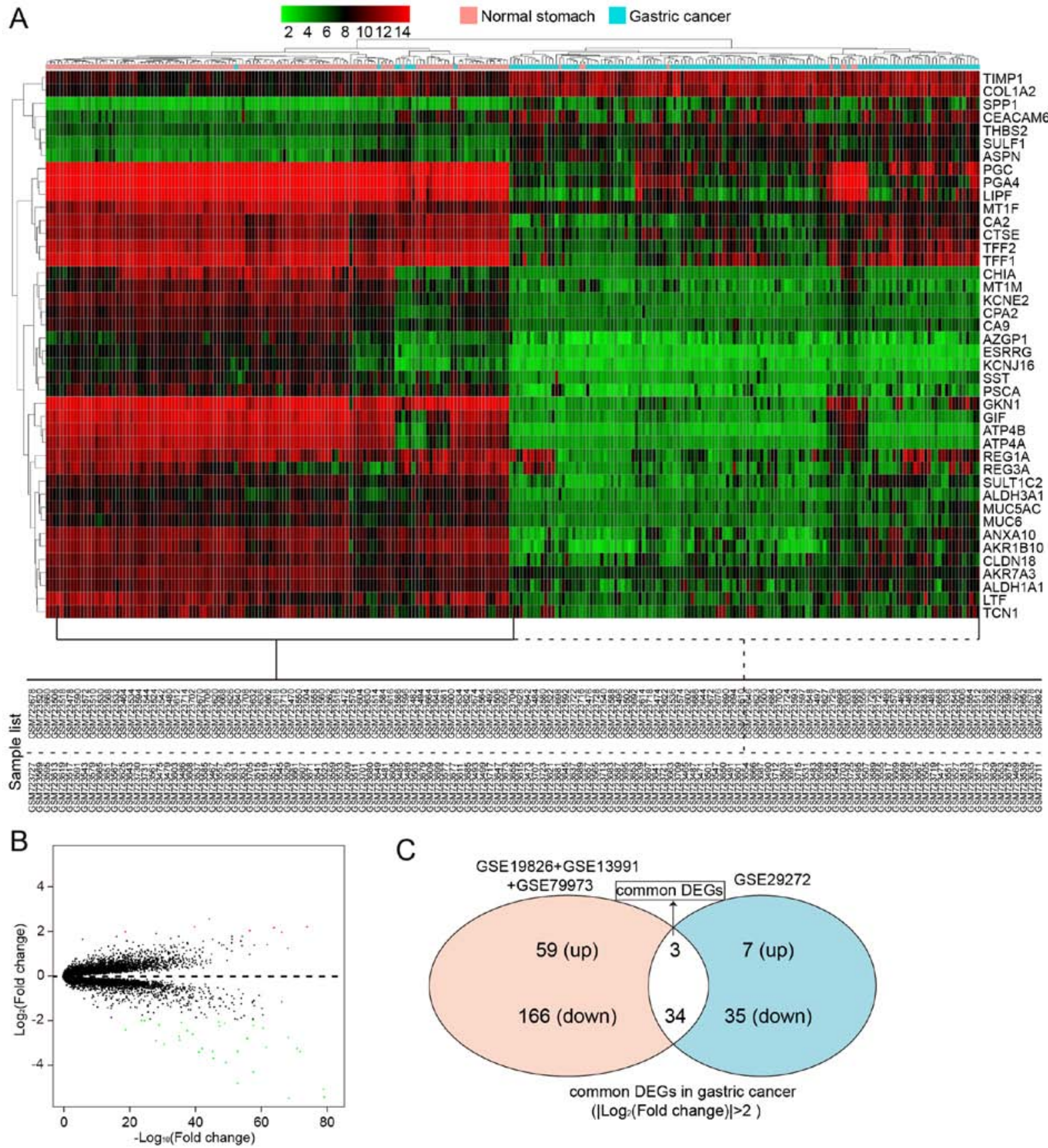

Figure 4. Results of differentially expressed genes (DEGs) filtered from GSE29272 on the GPL96 platform, and common DEGs screened out from the GPL570 and GPL96 platforms, respectively. (A) Heatmap of all DEGs from GSE29272. (B) Volcano plot of gene expression changes between gastric cancer (GC) tissues and controls from GSE29272. The red spots represent upregulated genes with a $\log _{2}$ (fold change)l of $>2$, and the green spots represent the downregulated genes with a $\log _{2}$ (fold change)l of $>2$. (C) Intersection of the DEGs in GC screened from the 2 sequencing platforms: GPL570 and GPL96. Upregulated DEGs are shown on the top row, and downregulated DEGs are shown on the bottom row.

reported that the majority of patients with advanced-stage GC experienced nutritional deficiency, which, in combination with surgical trauma, can easily cause post-operative immune dysfunction and malnutrition, imposing a certain influence on recovery, and this has been validated by a number of studies $(42,43)$. Functional analyses can help us to better understand the mechanisms of GC and may provide us with a guide to GC prevention and treatment. These pathways may be potential targets for improving the diagnosis and clinical effects in patients with GC.

However, further molecular biological experiments are required to confirm the function of the identified genes in GC and further analyses of other aspects in gastric carcinogenesis, such as epigenetic modification and single-nucleotide polymorphism (SNP) mutations (44) are also required. However, this study provides information for researchers which may aid in the identification of possible candidate genes and pathways which may be involved in GC. We provide further insight of gastric carcinogenesis at the molecular level and information of potential candidate biomarkers for the diagnosis, prognosis and drug targets for GC.

In conclusion, the present study utilized the analysis of whole genome sequencing results from different laboratories, and screened out the common DEGs from different sequencing 
A

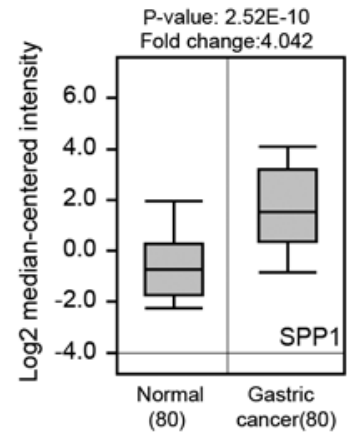

B

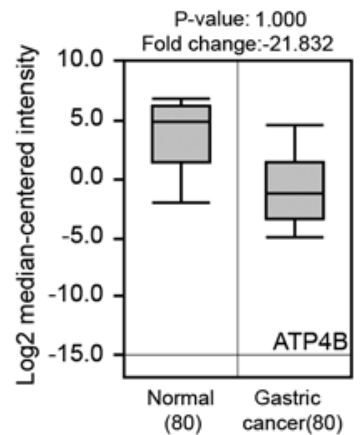

C

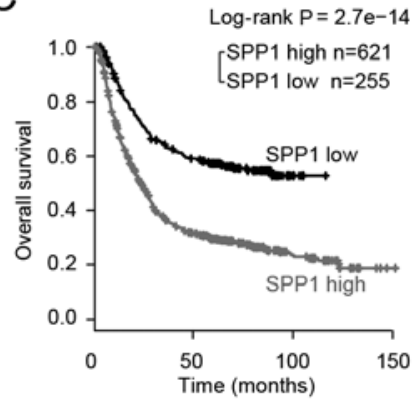

D

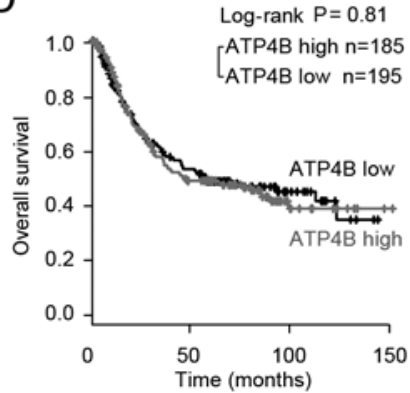

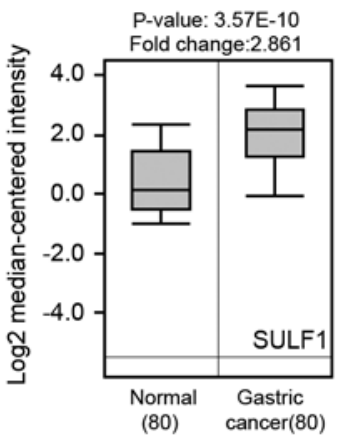
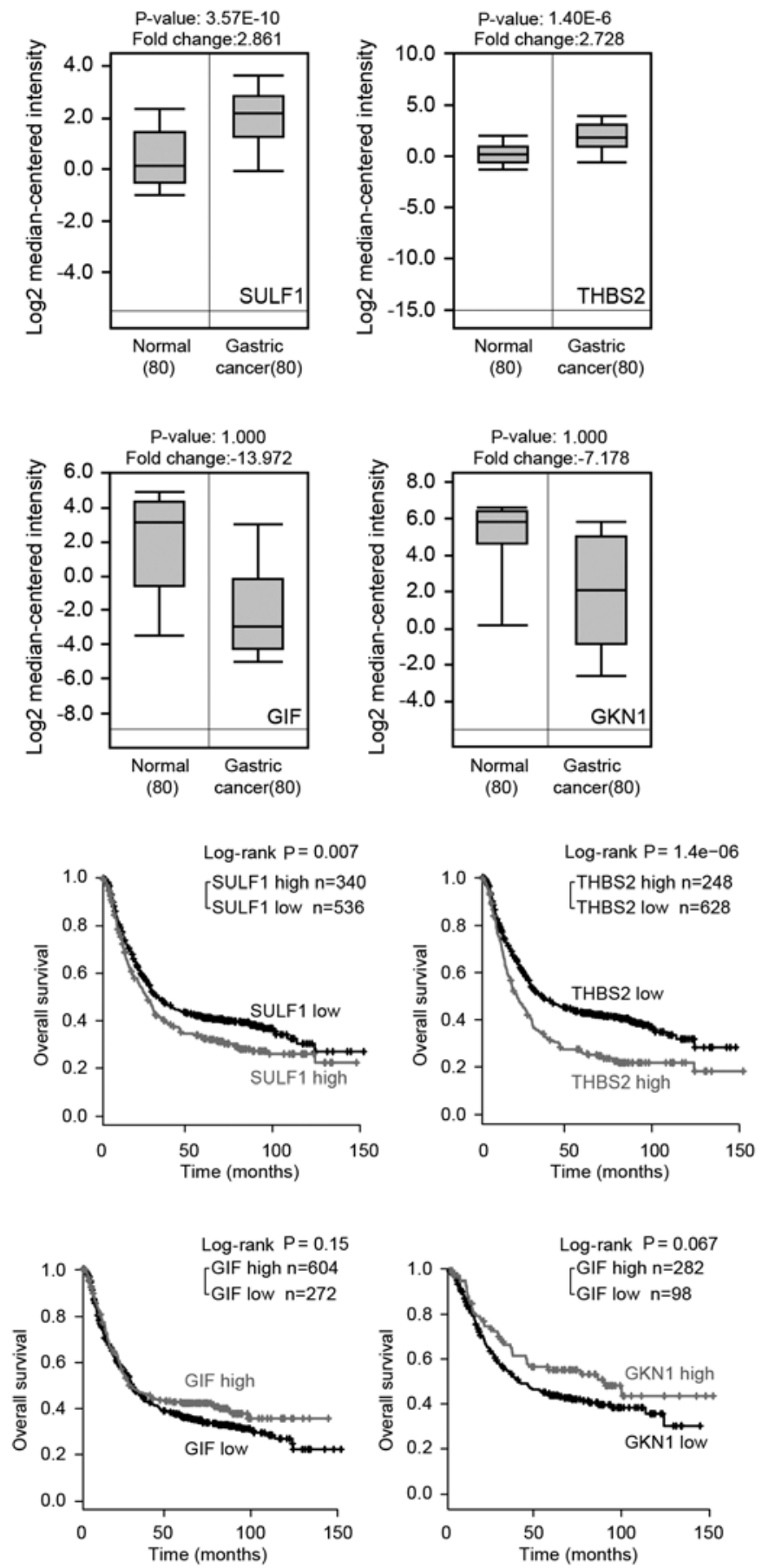

Figure 5. Upregulated differentially expressed genes (DEGs) are associated with a poor prognosis in gastric cancer (GC). (A) Box plots derived from gene expression data in Oncomine comparing the expression of the upregulated DEGs in normal tissues (left plot) and GC tissues (right plot). (B) Box plots derived from gene expression data in Oncomine comparing the expression of the downregulated DEGs in normal tissues (left plot) and GC tissues (right plot). (C) Kaplan-Meier plots of OS of patients with GC in whole datasets; patients with a high expression of upregulated DEGs exhibited a poor survival. Data were obtained from the Kaplan-Meier plotter database. The P-value was calculated by a log-rank test. (D) Kaplan-Meier plots of the OS of patients with GC in whole datasets; the association between the expression of downregulated DEGs and patient survival was not evident. Data were obtained from the Kaplan-Meier plotter database. The P-value was calculated by a log-rank test.

platforms containing 384 samples. There were 3 common upregulated DEGs and 34 common downregulated DEGs in $\mathrm{GC}$ with the threshold of $\log _{2} \mathrm{FCl}>2$ and $\mathrm{P}<0.05$. Functional analysis revealed that the downregulated DEGs were mainly involved in the digestion process, cellular aldehyde metabolic process, oxidation-reduction process, potassium ion imports and so on. Furthermore, the enriched KEGG pathways of downregulated DEGs included gastric acid secretion, collecting duct acid secretion and nitrogen metabolism. Through the analysis of all GSE series comparing GC cancer tissues and control in the GEO database, the prediction is more accurate and the bias of individual studies can be overcome. We also examined the association between the prognosis values and the common DEGs screened from 4 laboratories, and found that the common upregulated DEGs may play an important role in the development of GC. 
Table VII. Gene ontology analysis of downregulated genes in gastric cancer.

\begin{tabular}{|c|c|c|c|c|}
\hline Category & Term & Count & $\%$ & P-value \\
\hline GOTERM_BP_DIRECT & Digestion & 9 & 26.5 & $1.60 \mathrm{E}-13$ \\
\hline GOTERM_BP_DIRECT & Cellular aldehyde metabolic process & 4 & 11.8 & $9.30 \mathrm{E}-07$ \\
\hline GOTERM_BP_DIRECT & Potassium ion import & 3 & 8.8 & $1.20 \mathrm{E}-03$ \\
\hline GOTERM_BP_DIRECT & Protein catabolic process & 3 & 8.8 & $2.50 \mathrm{E}-03$ \\
\hline GOTERM_BP_DIRECT & Negative regulation of osteoclast development & 2 & 5.9 & $9.20 \mathrm{E}-03$ \\
\hline GOTERM_BP_DIRECT & Cobalt ion transport & 2 & 5.9 & $9.20 \mathrm{E}-03$ \\
\hline GOTERM_BP_DIRECT & Cobalamin transport & 2 & 5.9 & $1.50 \mathrm{E}-02$ \\
\hline GOTERM_BP_DIRECT & Secretion & 2 & 5.9 & $1.50 \mathrm{E}-02$ \\
\hline GOTERM_BP_DIRECT & Maintenance of gastrointestinal epithelium & 2 & 5.9 & $2.20 \mathrm{E}-02$ \\
\hline GOTERM_BP_DIRECT & Morphogenesis of an epithelium & 2 & 5.9 & $2.60 \mathrm{E}-02$ \\
\hline GOTERM_BP_DIRECT & Cobalamin metabolic process & 2 & 5.9 & $3.80 \mathrm{E}-02$ \\
\hline GOTERM_BP_DIRECT & Response to steroid hormone & 2 & 5.9 & $3.80 \mathrm{E}-02$ \\
\hline GOTERM_BP_DIRECT & One-carbon metabolic process & 2 & 5.9 & $5.40 \mathrm{E}-02$ \\
\hline GOTERM_BP_DIRECT & Proteolysis & 4 & 11.8 & $5.80 \mathrm{E}-02$ \\
\hline GOTERM_BP_DIRECT & Retina homeostasis & 2 & 5.9 & 7.30E-02 \\
\hline GOTERM_BP_DIRECT & Bicarbonate transport & 2 & 5.9 & 7.80E-02 \\
\hline GOTERM_BP_DIRECT & Oxidation-reduction process & 4 & 11.8 & $9.40 \mathrm{E}-02$ \\
\hline
\end{tabular}

Table VIII. KEGG pathway analysis of downregulated genes in gastric cancer.

\begin{tabular}{llcrr}
\hline Category & \multicolumn{1}{c}{ Term } & Count & $\%$ & P-value \\
\hline KEGG_PATHWAY & Gastric acid secretion & 6 & 17.6 & $8.8 \mathrm{E}-7$ \\
KEGG_PATHWAY & Collecting duct acid secretion & 3 & 8.8 & $2.2 \mathrm{E}-3$ \\
KEGG_PATHWAY & Nitrogen metabolism & 2 & 5.9 & $4.3 \mathrm{E}-2$
\end{tabular}
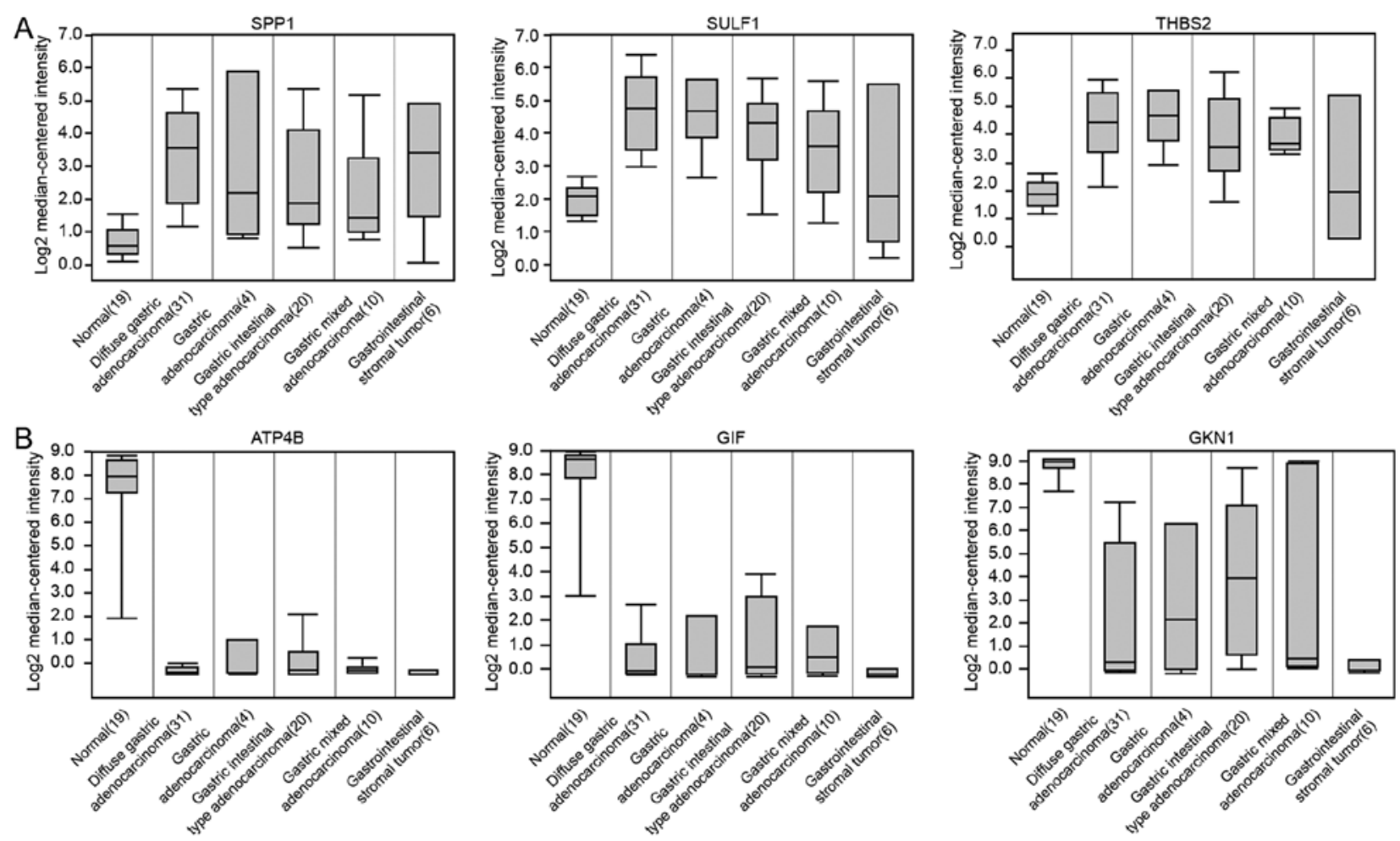

Figure 6. Upregulated differentially expressed genes (DEGs) are associated with a poor prognosis in different histological types of gastric cancer (GC). (A) Box plots derived from gene expression data in Oncomine comparing expression of the upregulated DEGs in normal tissues (first plot) and GC tissues (B) Box plots derived from gene expression data in Oncomine comparing the expression of the downregulated DEGs in normal tissues (first plot) and GC tissues. Numbers in parentheses means the number of patient tissues. 


\section{Acknowledgements}

The study was supported by the Doctoral Innovation Fund Projects from Shanghai Jiao Tong University School of Medicine (no. BXJ201404).

\section{Competing interests}

The authors declare that they have no competing interests.

\section{References}

1. Lordick F and Terashima M: Gastric cancer adjuvant therapy. Best Pract Res Clin Gastroenterol 30: 581-591, 2016.

2. Yoon $\mathrm{H}$ and Kim N: Diagnosis and management of high risk group for gastric cancer. Gut Liver 9: 5-17, 2015.

3. Gong EJ and Kim DH: Endoscopic ultrasonography in the diagnosis of gastric subepithelial lesions. Clin Endosc 49: 425-433, 2016

4. Xue H, Ge HY, Miao LY, Wang SM, Zhao B, Wang JR and Cui LG: Differential diagnosis of gastric cancer and gastritis: The role of contrast-enhanced ultrasound (CEUS). Abdom Radiol (NY) 42: 802-809, 2017.

5. Bass AJ, Thorsson V, Shmulevich I, Reynolds SM, Miller M, Bernard B, Hinoue T, Laird PW, Curtis C, Shen H, et al; Cancer Genome Atlas Research Network: Comprehensive molecular characterization of gastric adenocarcinoma. Nature 513: 202-209, 2014.

6. Badgwell B: Multimodality therapy of localized gastric adenocarcinoma. J Natl Compr Canc Netw 14: 1321-1327, 2016.

7. Ghadyalpatil NS, Supriya C, Prachi P, Ashwin D and Avanish S: Gastrointestinal cancers in India: Treatment perspective. South Asian J Cancer 5: 126-136, 2016.

8. Pasechnikov V, Chukov S, Fedorov E, Kikuste I and Leja M: Gastric cancer: Prevention, screening and early diagnosis. World J Gastroenterol 20: 13842-13862, 2014.

9. Lazăr DC, Tăban S, Cornianu M, Faur A and Goldiş A: New advances in targeted gastric cancer treatment. World J Gastroenterol 22: 6776-6799, 2016.

10. Riquelme I, Saavedra K, Espinoza JA, Weber H, García P, Nervi B, Garrido M, Corvalán AH, Roa JC and Bizama C: Molecular classification of gastric cancer: Towards a pathwaydriven targeted therapy. Oncotarget 6: 24750-24779, 2015.

11. Kothari N and Almhanna K: Current status of novel agents in advanced gastroesophageal adenocarcinoma. J Gastrointest Oncol 6: 60-74, 2015.

12. Zhang J, Huang JY, Chen YN, Yuan F, Zhang H, Yan FH, Wang MJ, Wang G, Su M, Lu G, et al: Erratum: Whole genome and transcriptome sequencing of matched primary and peritoneal metastatic gastric carcinoma. Sci Rep 5: 15309, 2015.

13. Hudler P: Challenges of deciphering gastric cancer heterogeneity. World J Gastroenterol 21: 10510-10527, 2015.

14. DeRisi JL, Iyer VR and Brown PO: Exploring the metabolic and genetic control of gene expression on a genomic scale. Science 278 . 680-686, 1997.

15. Golub TR, Slonim DK, Tamayo P, Huard C, Gaasenbeek M, Mesirov JP, Coller H, Loh ML, Downing JR, Caligiuri MA, et al: Molecular classification of cancer: Class discovery and class prediction by gene expression monitoring. Science 286: 531-537, 1999.

16. Barrett T, Wilhite SE, Ledoux P, Evangelista C, Kim IF, Tomashevsky M, Marshall KA, Phillippy KH, Sherman PM, Holko M, et al: NCBI GEO: Archive for functional genomics data sets - update. Nucleic Acids Res 41: D991-D995, 2013.

17. Ogata H, Goto S, Sato K, Fujibuchi W, Bono H and Kanehisa M: KEGG: Kyoto Encyclopedia of Genes and Genomes. Nucleic Acids Res 27: 29-34, 1999.

18. Rhodes DR, Yu J, Shanker K, Deshpande N, Varambally R, Ghosh D, Barrette T, Pandey A and Chinnaiyan AM: ONCOMINE: A cancer microarray database and integrated data-mining platform. Neoplasia 6: 1-6, 2004.

19. Rhodes DR, Kalyana-Sundaram S, Mahavisno V, Varambally R, Yu J, Briggs BB, Barrette TR, Anstet MJ, Kincead-Beal C, Kulkarni P, et al: Oncomine 3.0: Genes, pathways, and networks in a collection of 18,000 cancer gene expression profiles. Neoplasia 9: 166-180, 2007.
20. Gyorffy B,Lánczky A and Szállási Z: Implementing an online tool for genome-wide validation of survival-associated biomarkers in ovarian-cancer using microarray data from 1287 patients. Endocr Relat Cancer 19: 197-208, 2012.

21. Györffy B, Lanczky A, Eklund AC, Denkert C, Budczies J, Li Q and Szallasi Z: An online survival analysis tool to rapidly assess the effect of 22,277 genes on breast cancer prognosis using microarray data of 1,809 patients. Breast Cancer Res Treat 123: 725-731, 2010.

22. Correa P: A human model of gastric carcinogenesis. Cancer Res 48: 3554-3560, 1988.

23. Holbrook JD, Parker JS, Gallagher KT, Halsey WS, Hughes AM, Weigman VJ, Lebowitz PF and Kumar R: Deep sequencing of gastric carcinoma reveals somatic mutations relevant to personalized medicine. J Transl Med 9: 119, 2011.

24. Lim B, Kim JH, Kim M and Kim SY: Genomic and epigenomic heterogeneity in molecular subtypes of gastric cancer. World $\mathrm{J}$ Gastroenterol 22: 1190-1201, 2016.

25. Pfeifer SP: From next-generation resequencing reads to a highquality variant data set. Hered Edinb 118: 111-124, 2017.

26. Raja UM, Gopal G and Rajkumar T: Intragenic DNA methylation concomitant with repression of ATP4B and ATP4A gene expression in gastric cancer is a potential serum biomarker. Asian Pac J Cancer Prev 13: 5563-5568, 2012.

27. Yang M, Jiang N, Cao QW, Ma MQ and Sun Q: The E3 ligase UBR5 regulates gastric cancer cell growth by destabilizing the tumor suppressor GKN1. Biochem Biophys Res Commun 478: 1624-1629, 2016.

28. Yoon JH, Choi WS, Kim O, Choi BJ, Nam SW, Lee JY and Park WS: Gastrokine 1 inhibits gastric cancer cell migration and invasion by downregulating RhoA expression. Gastric Cancer 20: 274-285, 2017.

29. Kim O, Yoon JH, Choi WS, Ashktorab H, Smoot DT, Nam SW, Lee JY and Park WS: Gastrokine 1 inhibits gastrin-induced cell proliferation. Gastric Cancer 19: 381-391, 2016.

30. Xing R, Cui JT, Xia N and Lu YY: GKN1 inhibits cell invasion in gastric cancer by inactivating the NF-kappaB pathway. Discov Med 19: 65-71, 2015.

31. Wu W, Juan WC, Liang CR, Yeoh KG, So J and Chung MC: S100A9, GIF and AAT as potential combinatorial biomarkers in gastric cancer diagnosis and prognosis. Proteomics Clin Appl 6: $152-162,2012$.

32. Kong Y, Zheng Y, Jia Y, Li P and Wang Y: Decreased LIPF expression is correlated with DGKA and predicts poor outcome of gastric cancer. Oncol Rep 36: 1852-1860, 2016.

33. Wang D, Yu X and Wang X: High/positive expression of 5-fluorouracil metabolic enzymes predicts better response to S-1 in patients with gastric cancer: A meta-analysis. Int J Biol Markers 31: e101-e109, 2016.

34. Hunt RH, Camilleri M, Crowe SE, El-Omar EM, Fox JG, Kuipers EJ, Malfertheiner P, McColl KE, Pritchard DM, Rugge M, et al: The stomach in health and disease. Gut 64: 1650-1668, 2015.

35. Di Mario F and Goni E: Gastric acid secretion: Changes during a century. Best Pract Res Clin Gastroenterol 28: 953-965, 2014.

36. Martinsen TC, Bergh K and Waldum HL: Gastric juice: A barrier against infectious diseases. Basic Clin Pharmacol Toxicol 96: 94-102, 2005.

37. Modlin IM, Sachs G, Wright $\mathrm{N}$ and Kidd M: Edkins and a century of acid suppression. Digestion 72: 129-145, 2005.

38. Wagner CA and Geibel JP: Acid-base transport in the collecting duct. J Nephrol 15 (Suppl 5): S112-S127, 2002.

39. Alper SL: Genetic diseases of acid-base transporters. Annu Rev Physiol 64: 899-923, 2002.

40. Li JH, Han L, Du TP and Guo MJ: The effect of low-nitrogen and low-calorie parenteral nutrition combined with enteral nutrition on inflammatory cytokines and immune functions in patients with gastric cancer: A double blind placebo trial. Eur Rev Med Pharmacol Sci 19: 1345-1350, 2015.

41. Ishizuka M, Oyama Y, Abe A, Tago K, Tanaka G and Kubota K: Prognostic nutritional index is associated with survival after total gastrectomy for patients with gastric cancer. Anticancer Res 34: 4223-4229, 2014.

42. Tegels JJ, De Maat MF, Hulsewé KW, Hoofwijk AG and Stoot JH: Improving the outcomes in gastric cancer surgery. World J Gastroenterol 20: 13692-13704, 2014.

43. Sun K, Chen S, Xu J, Li G and He Y: The prognostic significance of the prognostic nutritional index in cancer: A systematic review and meta-analysis. J Cancer Res Clin Oncol 140: 1537-1549, 2014

44. Kang C, Song JJ, Lee J and Kim MY: Epigenetics: An emerging player in gastric cancer. World J Gastroenterol 20: 6433-6447, 2014. 